\title{
Voicing Is Costly, but Team Can Change That: A Three-Wave Study on Employee "Voice" through the Lens of the Theory of Planned Behavior
}

\author{
Masaki Matsunaga ${ }^{1, *}$ \\ ${ }^{1}$ Robert T. Huang Entrepreneurship Center, Kyushu University, Fukuoka, Japan \\ *Correspondence: Robert T. Huang Entrepreneurship Center, Kyushu University, Fukuoka, Japan. E-mail: \\ matsunaga@qrec.kyushu-u.ac.jp
}

Received: Decmeber 4, 2016

Accepted: Decmeber 21, 2016 Online Published: Decmeber 23, 2016

doi:10.5430/mos.v4n1p10

URL: http://dx.doi.org/10.5430/mos.v4n1p10

\begin{abstract}
Despite the rich literature on employee "voice"-an organizational behavior of speaking up with intentions to improve one's work processes - the underlying structure that integrates the effects of related factors has yet to be explored. In addition, previous studies almost exclusively focus on whether organizational members speak up, leaving the issue of how they communicate their "voice" unattended. To address those limitations, this study examined three-wave longitudinal data collected from 539 full-timers working at 106 enterprises in Japan, using multi-level structural equation modeling (ML-SEM) and latent profile analyses (LPA). The ML-SEM results indicated that: (a) perceived cost-benefit balances and subjective norms (but not communication efficacy), as well as leader-member exchange (LMX), are associated with "voice" intentions; (b) LMX quality's effects are partially mediated via psychological factors; and (c) group-level LMX differentiation added to the model's explanatory power above and beyond the individual-level predictors. Additionally, LPA detected five distinct patterns of employee "voice" communication (or lack thereof). Those analyses revealed that direct communication is rather atypical, and many individuals utilize indirect strategies, such as only disclosing parts of their opinions first to test the water or telling colleagues who they think will eventually convey revealed ideas to leaders.
\end{abstract}

Keywords: employee "voice;" Japan; Latent Profile Analysis (LPA); leader-member exchange; Multi-Level Structural Equation Modeling (ML-SEM); theory of planned behavior

\section{Introduction}

Upward communication is an important organizational behavior. Organizations where members actively venture to speak up and discuss work-related matters with their leaders enjoy favorable outcomes, such as better decision-making, effective organizational learning, and efficient use of talent and human resources (Brinsfield, Edwards, \& Greenberg, 2009; Edmondson, 2003; Mesmer-Magnus \& DeChurch, 2009). On the other hand, research shows that employees' avoidance of upward communication, or silence, has negative implications for group performance and work ethics (Morrison \& Milliken, 2000).

More often than not, however, do employees shy away from voicing opinions and ideas to their supervisor, even if they were confident that those suggestions would lead to improvement of work processes. In fact, "speaking up" is typically seen as a risky, if heroic, behavior by organizational members (Detert \& Burris, 2007; Milliken, Morrison, \& Hewlin, 2003). Although previous studies have identified a number of individual- and group-level variables associated with this phenomenon, more research is needed to further explore the psychological, relational, and communicative dynamics related to the "To Tell or Not to Tell" conundrum at workplace (Morrison, Wheeler-Smith, \& Kamdar, 2011; Venkataramani \& Tangirala, 2010).

In an attempt to address this exigency, the current research aims to explore the underlying structure of employee "voice" behavior. To do so, this study draws on influential theories on decision-making and leader-member exchanges, with Ajzen's (1991) theory of planned behavior (TPB) as an overarching framework. In addition, to address Morrison et al.'s (2011: 190) call for the "research that looks not just at the extent to which people voice but also at how and what they voice," this study employs a recently proposed typology of risky revelation strategies 
(Afifi \& Steuber, 2009) and examines how TPB and other related theories help predict organizational members' "voice" communication patterns.

This study will contribute to the development of theoretical understanding and practical knowledge related to "voice" in at least three ways. First, by analyzing data through the lens of TPB, it sheds fresh light on the phenomenon of employee "voice," as most existing studies are conducted from the social-exchange perspective (e.g., Aryee, Budhwar, \& Chen, 2002) and TPB-based research is relatively rare. Second, this study contributes to the development of TPB literature by establishing a framework that integrates TPB with recently developed theories on human decision-making, group dynamics, and communication strategies for information management at work settings. Finally, findings from this study will bring a number of practical implications by identifying related factors of "voice" behavior and the structure undergirding their effects. Such implications will help inform managers about psychological mechanisms operating behind employee "voice" (or lack thereof) and provide useful hints about how leaders can encourage members to open up and share their ideas. With those goals in mind, relevant literature is reviewed in turn below; following this review, a longitudinal study that has examined the underlying structure of employees" "voice" behavior at enterprises in Japan is reported.

\subsection{Employee "Voice"}

The construct of "voice" as an organizational behavior has been defined in various ways (Brinsfield et al., 2009; Van Dyne, Ang, \& Botero, 2003). This study draws on the following conceptualization: "employees' expressions of constructive challenges to others in their work groups regarding issues of work efficiency, with intentions to improve rather than merely to criticize" (Van Dyne \& LePine, 1998: 109). For example, it may include bringing important concerns to the leader's attention or suggesting a change in the current operational procedures to achieve greater efficiency. It should be noted that the label of "voice" is used metaphorically, and thus, it is not limited to verbally expressed messages. In fact, the construct of "voice" covers any communicative behaviors that are voluntarily enacted by organizational members to critically examine existing practices/others with an intention to improve their organization's functionality.

"Voice" is a provocative behavior because, by nature, it calls into question the validity of the current practices, decisions, and/or structure of one's work group (Detert \& Burris, 2007). In addition, when employees engage in "voice" behaviors, its target is usually their supervisors, who hold the power to sway the respective employees" working conditions (Ashford, Sutcliffe, \& Christianson, 2009). Naturally, it is difficult for employees to "voice." Detert and Edmondson (2011) found that employees hold a variety of implicit theories, or taken-for-granted beliefs, about when and why speaking up at work is risky and inappropriate. Those scholars argue that this risk associated with "voice" is grounded in employees' beliefs rather than organizations' institutionalized systems. That is, even when supervisors explicitly seek feedback and there is no way to induce penalty, organizational members still resist abandoning their beliefs about the risk of speaking up (see also Harlos, 2001; Kish-Gephart, Detert, Trevino, \& Edmondson, 2009).

Literature suggests a number of individual- and group-level factors associated with employee "voice." For example, employees who are high on risk-taking tendency, play a central role in the work-flow, and/or have a high leader-member exchange (LMX) status tend to "voice" more readily, especially when their leader is open-minded and receptive to suggestions for change (Burris, Detert, \& Chiaburu, 2008; LePine \& Van Dyne, 2001; Venkataramani \& Tangirala, 2010). Group-level variables such as organizational structure, procedural fairness, and justice climate also affect employee "voice" behavior (Brockner et al., 2001; Tangirala \& Ramanujam, 2008). Milliken and colleagues' research has shown that, in organizations that are highly hierarchical and centralized, upward communication is scarce and silence is commonly chosen by employees (Milliken et al., 2003; Morrison \& Milliken, 2000).

Thus accumulated findings notwithstanding, the underlying mechanism that integrates the effects of the aforementioned variables is still to be explored. In addition, most existing studies almost exclusively focus on predicting the frequency of "voice" (i.e., whether employees express their opinions or not), whereas the issue of how organizational members communicate to "voice" is largely left unattended (Morrison et al., 2011). The current study aims to fill this void in the literature by drawing on the theory of planned behavior (Ajzen, 1991) as an overarching analytical framework to examine employees' decision-making process regarding "voice" behavior and incorporating Afifi and Steuber's (2009) typology of risky revelation strategies. 


\subsection{Theory of Planned Behavior}

Theory of planned behavior (TPB) specifies the psychological processes through which individuals evaluate their surrounding environments, form decisions, and execute behaviors. According to TPB, when individuals decide on whether and how they should engage in high-stake acts, several mutually-related psychological factors - including attitudes, perceived control, and heuristics such as subjective norms - affect the individuals' intentions to execute the act in question and those intentions, in turn, lead to their future behavior (Ajzen, 1991).

The first determinant of intentions specified in the TPB is attitude, defined as the extent to which individuals see a particular act in the positive or negative light (Ajzen \& Madden, 1986). Naturally, the more positively individuals evaluate the act in question, the more likely they will engage in it. The second determinant is the perceived control, or individuals' confidence that they can successfully cause the change they intend by their own measures (Fishbein \& Ajzen, 2010). As a conceptualization of this construct, this study highlights the notion of communication efficacy, which refers to context-specific perceptions about individuals' capability of making themselves understood and convincing their interactional counterpart of their ideas, needs, and/or worldviews at a given setting (Afifi \& Steuber, 2009; Bandura, 1997). Finally, TPB suggests that individuals draw on some heuristics, or subjective norms, as they make decisions. That is, individuals consider whether others will support their intended behavior or disapprove it, and expected disapproval from those in the surrounding environment is known to provide a powerful deterrent (Guo et al., 2006; Rimal \& Real, 2005; Welbourne \& Booth-Butterfield, 2005).

Key assumption here is that the behavior under consideration should involve stake and risks that are high enough to motivate individuals to undertake complex psychological processing. Disentangling various influences of the factors identified by TPB can be psychologically taxing. Accordingly, individuals invest their mental resources to do so only in high-stake situations, where poor handling is likely to beget a severe consequence (Fishbein \& Ajzen, 2010). The target phenomenon of this study is argued to qualify as one such high-stake situation because, as noted earlier, "voice" can be regarded as an aggressive behavior that might invite unwanted attentions and cause plaguesome troubles with one's supervisor (Ashford et al., 2009; Detert \& Burris, 2007). This relevance suggests that TPB should provide a useful guideline to analyze individuals' "voice" behavior at work. Accordingly, the hypothesis below is set forth based on TPB as an overarching analytical framework for the current research:

Hypothesis 1. Individuals' attitudes, communication efficacy, and subjective norms are associated with their intention to "voice," which, in turn, predicts the actual enactment of their "voice" behavior at work settings.

At the same time, recent development of theories about human decision-making, group dynamics, and information management indicates that those TPB concepts identified above can be further expanded. It is to this emerging body of literature this review now turns.

\subsection{Attitudes, Cost-Benefit Balance, \& Lost Opportunities}

Traditionally, TPB research has conceptualized attitudes as individuals' psychological calculation of the cost-benefit balance regarding the behavior under consideration (Ajzen, 1991). This is argued to be a limited scope, however, because it fails to take into account the dilemma associated with deferring the decision-making. When making decisions in a high-stake situation, individuals not only consider the consequence of taking an action but they also mull over the cost-benefit balance of missing/passing the opportunity to execute the respective behavior.

As epitomized in sayings such as "the fish you let escape is always big" or "seize the fortune by the forelock," lingering affection of lost chance poses significant impact, especially when the likelihood to obtain the same chance in the future is small (Northcraft \& Neale, 1986; Payne, Bettman, \& Luce, 1996). Elaborating on this notion, O'Keefe (2002) notes that persuasive messages stressing the cost of missing an opportunity are more effective than those emphasizing the benefit of taking a chance, suggesting the existence of distinct mechanisms that evaluate the cost-benefit balance for taking an opportunity and that for missing it.

In a related vein, the theory of loss aversion suggests that individuals typically prefer status quo over change, and therefore, just perceiving the benefit of an action might be insufficient as an impetus (McGraw, Larsen, Kahneman, \& Schkade, 2010; Samuelson \& Zeckhauser, 1988; Tversky \& Kahneman, 1991). On the other hand, seeing the disadvantage of missing an opportunity should provide a powerful behavioral driver because loss poses greater affective impact than gain (Kermer, Driver-Linn, Wilson, \& Gilbert, 2006).

These analyses suggest that the extant TPB studies might have missed capturing the full potential of the attitude factor, because they exclusively focus on the cost-benefit balance of executing a behavior under consideration and the issue of missing opportunities is typically left out of research scope. The current study examines this surmise by distinguishing the cost-benefit balance of action (i.e., "voice") and that of inaction (i.e., "silence," or intentional 
avoidance of engaging in "voice" behavior; Van Dyne et al., 2003). Previous findings reviewed in this section suggest that those two considerations do not constitute opposite ends of the same continuum; rather, they should operate as distinct psychological mechanisms that exert unique effects on individuals' decision-making process. Stated formally:

Hypothesis 2. Cost-benefit balance of "voice" and that of "silence" are both uniquely associated with individuals" intentions to express constructive challenges at work.

\subsection{Leader-Member Exchange (LMX) Quality and "Voice” Dynamics}

\subsubsection{LMX Quality}

Another conceptual domain to expand the TPB framework in relation to "voice" concerns employees' workplace relationships. In particular, this study highlights the leader-member exchange (LMX; Liden, Sparrowe, \& Wayne, 1997), or the perceived quality of the relationship forged between employees and their supervisor/leader. Literature suggests that leaders do not form identical relationships with all members, since members differ in the loyalty, expertise, and respect they offer (Gerstner \& Day, 1997; Liden \& Maslyn, 1998). Unsurprisingly, individuals who can offer those affective and instrumental currencies for exchange more than others tend to achieve a higher LMX status; thus established high-LMX status, in turn, leads to select assignment to challenging tasks, faster promotion advancement, and increased influence within the organization (Scandura \& Schriescheim, 1994; Sparrowe \& Liden, 2005).

Naturally, high-LMX employees are regarded by their supervisor as indispensable talent (Erdogan, Kraimer, \& Liden, 2004), and this standing makes it more feasible for them to engage in "voice." For one reason, high-LMX individuals are often admitted greater behavioral freedom and less likely to face a reprimand, even when they engage in provocative or confrontational behaviors at work. As such, a high-LMX status is argued to provide a buffer to mitigate the cost associated with "voice." Additionally, high-LMX employees would feel stronger subjective norms toward "voice." Such individuals typically occupy a central position and play critical roles in the work flow, and therefore, others at work tend to expect them to take initiatives and support if they speak up (Venkataramani \& Tangirala, 2010). Finally, high-LMX individuals are more likely to find hearing ears among leaders because they have frequent contact with supervisors and know well how to communicate with them (Kacmar, Witt, Zivnuska, \& Gully, 2003). This perceived ease would enhance employees' communication efficacy. According to TPB, those enhanced psychological states and perceptions should, in turn, encourage individuals to engage in "voice" behaviors more readily. Therefore, the following mediational hypothesis is set forth:

Hypothesis 3. Perceived LMX quality is positively associated with enhanced levels of the cost-benefit balance, subjective norms, and communication efficacy for "voice," and those enhanced perceptions would, in turn, account for individuals" "voice” intentions.

\subsubsection{LMX Differentiation}

LMX also stirs leader-member communication by setting up the workplace climate. Recent studies indicate that the within-group variance of LMX levels in a given unit, called LMX differentiation, has potential to affect employees above and beyond the effects of dyad-level LMX (Henderson, Liden, Glibkowski, \& Chaudhry, 2009; Hooper \& Martin, 2008; Liden, Erdogan, Wayne, \& Sparrowe, 2006). LMX differentiation per se is a natural process of management, because it in part stems from ordinary role differentiations (Dienesch \& Liden, 1986). Nonetheless, excessive LMX differentiation indicates that leaders invest efforts to develop relationships only with particular employees and distribute vocational resources unevenly within the work group. Employees under such style of leadership tend to ingratiate rather than challenge the leader, because arousing her or his antipathy can result in losing the access to the loop of information, influence, and resource distribution associated with a high-LMX status (Erdogan \& Bauer, 2010; Simons \& Roberson, 2003).

Psychological climate theory offers a theoretical account for those patterns (James, James, \& Ashe, 1990). According to this theory, contextual factors that reflect ambient yet significant characteristics of a work group affect members' attitudes and behaviors as they attach meanings to those factors, and thus generated attributions specify the members' cognitions, behavioral preferences, and value judgment (James, James, \& Ashe, 1990). For example, Mathieu and colleagues found that group-level situational constraints are associated with individuals' job performance via self-efficacy (i.e., constraints are associated with efficacy, which, in turn, leads to performance) (Mathieu, Martineau, \& Tannenbaum, 1993).

It seems reasonable to posit that LMX differentiation provides an important contextual factor related to employee "voice." Given its features noted earlier, large LMX differentiation should work to discourage "voice." This is 
because, the greater the LMX differentiation, the riskier it is to incur the displeasure of the supervisor and thereby lose a high-LMX status (and resources accompanying such a status). Further, this psychological mechanism should affect not only the employees with a low-LMX status but also those with a high-LMX status, because all employees belonging to the same work group are, by definition, exposed to the same level of the LMX differentiation. It stands to reason that overly large LMX differentiation works to deter employee "voice" behavior above and beyond the effects of individual-level factors, via its impact on the related psychological factors (Ashford et al., 2009; Detert \& Burris, 2007; Hooper \& Martin, 2008). Hence, the following hypothesis:

Hypothesis 4. LMX differentiation accounts for individuals' "voice" intentions via its associations with the cost-benefit balance, subjective norms, and communication efficacy, above and beyond the effects of individual-level LMX perceptions.

Together, Hypotheses 2 through 4 expand the framework of TPB by integrating theories about human decision-making and LMX/LMX differentiation. Figure 1 illustrates the interrelationships among the factors postulated in this expanded model.
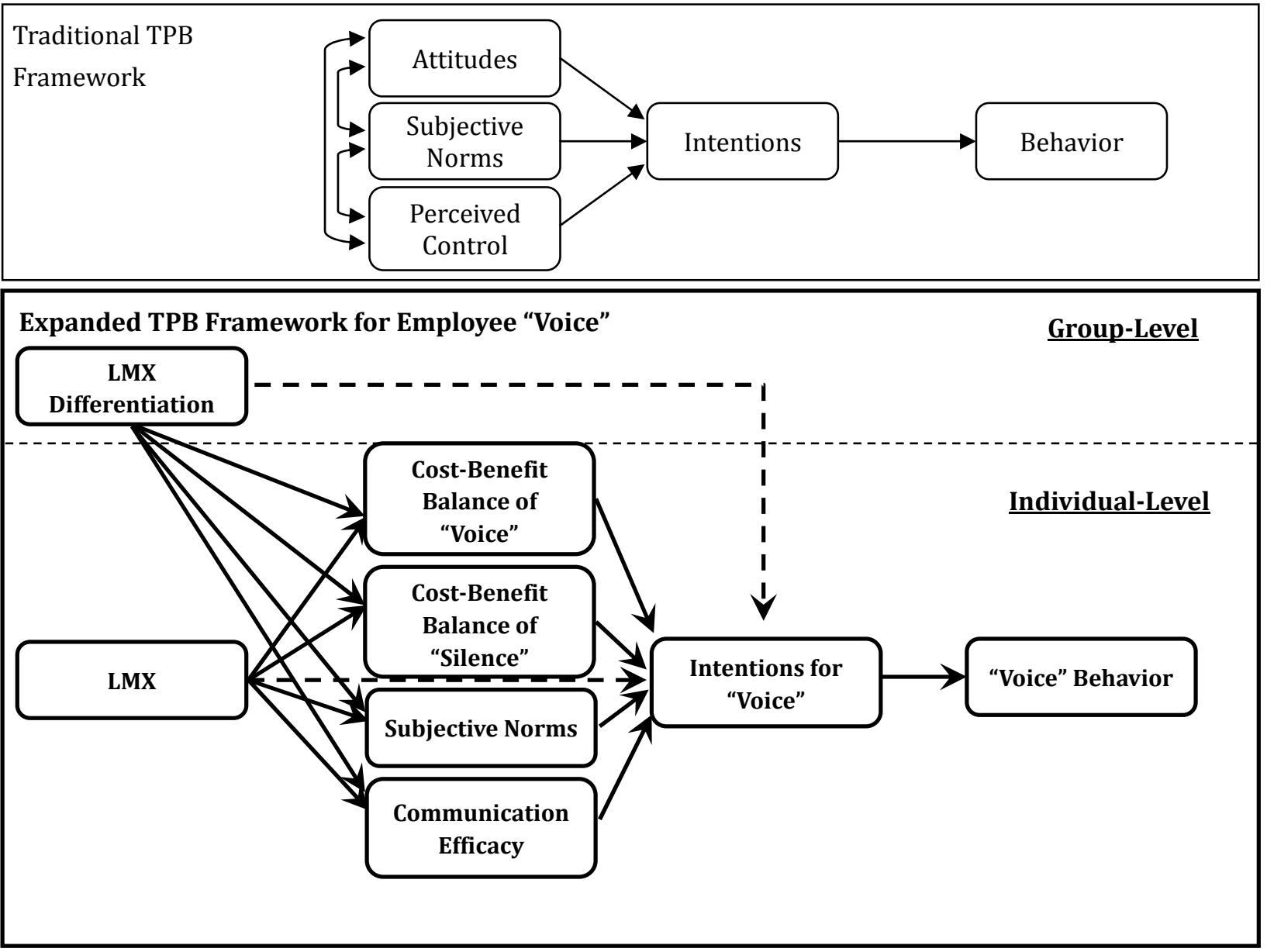

Figure 1. Expansion of TPB Framework and the Hypothesized Structure Underlying Employee "Voice"

Note. Single-headed arrows indicate hypothesized causal paths. Double-arrow-headed arcs indicate non-directional associations.

\subsection{Communication Strategies for Employee "Voice"}

Finally, this study explores how individuals communicate when they choose to "voice." Morrison et al. (2011) point out that the majority of the existing studies on "voice" devote their efforts to predicting whether employees speak up or not; as a result, little is known about how they actually communicate their "voice." Research in the relevant fields of interpersonal communication suggests that, when individuals communicate potentially threatening or risky 
information, they tend to be highly aware of competing needs of the involved parties and utilize various strategies to address them (Afifi \& Caughlin, 2006; Omarzu, 2000; Petronio, 2002; Vangelisti, Caughlin, \& Timmerman, 2001).

People indeed employ a range of strategies to achieve their interactional goals without being inappropriate or offending others (Afifi \& Steuber, 2009; Edgar, 1994). Generally, individuals prefer indirect strategies to communicate high-stake information in enduring relationships, because the ramifications would be long-lasting (Berger, 1997; Roloff \& Cloven, 1990). Indirect strategies are useful to maintain deniability, save face of the interlocutors, and avoid unnecessary frictions; at the same time, indirect communication has its own risks, such as being misunderstood, failure to catch attention, and/or causing frustration due to the weariness of communication. Thus, under certain circumstances, individuals venture to use more explicit messages and engage in direct communication styles (Petronio, 1991, 2002). Further, people sometimes experiment by disclosing only partial information at first and examining their counterpart's response to decide whether and how they should proceed (Frattaroli, 2006).

Based on previous studies and also on their own research, Afifi and Steuber (2009) have identified six distinct strategies. The first strategy, Directness, refers to communicating one's thoughts to the target in face-to-face (F2F) settings. A second strategy is incremental disclosure, which s similar to Frattaroli's (2006) notion of "experimental disclosure" and involves revealing only bits and pieces of one's ideas at first to gauge the target person's reactions. Preparation and rehearsal refers to sharing ideas with someone such as one's colleagues first, developing a script, and then revealing it to the target. A fourth strategy is third-party revelations, which involves sharing ideas with a third party, who individuals believe will eventually convey the ideas to the target person. Fifth, individuals are said to use the "entrapment" strategy when they intentionally leave evidence/trace of their thoughts (e.g., scribbles on a note or memo), hoping the target person will find it. Finally, individuals might use indirect mediums by disclosing via non-F2F media such as telephones, e-mails, or postings on social networks (Afifi \& Steuber, 2009).

Because few studies have examined specific communication strategies people use to enact "voice" behavior at work settings (Morrison et al., 2011), the current study draws on Afifi and Steuber's (2009) typology illustrated above and explores the following research question:

Research Question. What are the major patterns of communication strategies employees use to enact "voice" at work, and how are those patterns associated with the employees' attitudes, communication efficacy, and subjective norms, as well as "voice" intentions?

\section{Method}

\subsection{Participants \& Procedures}

A total of 539 individuals working at 106 for-profit enterprises in Japan responded to three online surveys for the current research (age $M=28.4 \mathrm{yrs}, S D=5.1$; female $n=298$, or $55.3 \%$ ). Recruiting was arranged such that three to 10 employees belonging to the same work unit of a company (average $n$ per unit $=5.1$ ) under the same supervisor (supervisor age $M=42.5 \mathrm{yrs}, S D=3.8$ ) participated. They received the recruitment e-mail individually (see below) and completed the surveys independently at their convenient time. Their average tenure at the current organization was 6.6 years $(S D=4.5)$. Approximately $11 \%(n=61)$ held an MBA. Those individuals belonged to enterprises in a variety of industry domains, including service industries, manufacturing, and IT/technology, to name a few. Those who did not have regular contact with the immediate supervisor or did not belong to a work unit consisting of multiple members (i.e., freelance/independent specialist) were excluded from the recruitment procedure.

The author initially contacted 700 individuals registered as paid-panel respondents of a large marketing research company, which collaborated with the current research (this study is a part of a larger research project, but only the data and findings that are considered relevant to this study are reported in the current manuscript). This initial message included informed consent, explanation about confidentiality, and the link to Wave- 1 survey website. This survey assessed the participants' demographics and general information about their job and workplace, including LMX. In addition, participants were asked to describe one "voice" topic - a work-related issue which they had not discussed with their supervisor as of the time of Wave-1 survey completion but they think it should be brought to her/his attention to improve their work unit's functionality (Van Dyne \& LePine, 1998). Then, with this topic in mind, the participants completed the survey tapping their attitudes, communication efficacy, and subjective norms.

The second survey was administered two weeks later, an interval long enough to assume that most respondents would not be able to recall previous responses, hence minimizing the effects of sensitization and self-consistency bias (Menard, 2002). Wave-2 survey first displayed the "voice" topic provided in Wave-1 survey and asked whether 
they had already discussed it at work. The participants then indicated the degree of their intentions to "voice" the respective topic within two weeks. Only seven individuals had "voiced" between Waves 1 and 2; their data were not analyzed for this study to maintain a clean longitudinal structure of the model (cf. Figure 1).

Finally, Wave-3 survey was administered after another 2-week interval. This survey again displayed the "voice" topic provided at Wave 1 and asked the participants if they had used any of Afifi and Steuber's (2009) risky revelation strategies with their supervisor as the target. Upon completion of Wave-3 survey, the participants were thanked and debriefed. They all received electronic coupon as a token of appreciation. Removing those who had stopped responding during the three waves, the effective response rate was $77.0 \%$ (final $n=539$ ).

\subsection{Measures}

As noted above, Wave-1 survey assessed respondents' perceived LMX quality, attitudes, communication efficacy, and subjective norms, as well as other basic information; intention for "voice" was assessed in Wave-2; and Wave-3 survey assessed their communication strategy use. All measures were translated into Japanese using Brislin's (1970) method.

\subsubsection{LMX \& LMX Differentiation}

LMX was assessed using Scandura and Graen's (1984) items on a 7-point Likert-type scale ( 1 = Strongly disagree; 7 $=$ Strongly agree). Example item included "My supervisor understands my problems and needs" $(\alpha=.90)$. Further, within-group variance in LMX for each work group was calculated to operationalize LMX differentiation.

\subsubsection{Subjective Norms}

Three items developed by Davis, Ajzen, Saunders, and Williams (2002) were modified to fit this study's context and used to assess individuals' subjective norms. Example item included "I think most people at my workplace would support me if I speak up to suggest a change for improvement of our work processes" $(\alpha=.85)$.

\subsubsection{Attitudes}

This study followed Davis et al.'s (2002) procedure to tap the perceived cost-benefit balances of "voice" and "silence." Specifically, respondents were asked to indicate their attitudes toward those behaviors using four items on a 7-point semantic-differential scale. Example items included "punishing-rewarding", "harmful-beneficial", and "bad-good." Reliabilities for the attitudes toward "voice" and "silence" were .87 and .88 , respectively.

\subsubsection{Communication Efficacy}

This study adopted items from Afifi and Caughlin's (2006) scale to measure individuals' communication efficacy to "voice" at work. Assessment was made on a 7-point Likert-type scale ( $1=$ Strongly disagree; $7=$ Strongly agree $)$ and example item included "I am confident that I know how to approach the issue with my boss" $(\alpha=.92)$.

\subsubsection{Intentions}

Three items developed by Davis et al.'s (2002) were modified and used in Wave-2 survey to assess individuals' intentions to "voice" on a 7-point Likert-type scale $(1=$ Strongly disagree; $7=$ Strongly agree $)$. Example item included "If I have a chance over the next two weeks, I will try to discuss the issue with my supervisor" $(\alpha=.90)$.

\subsubsection{Strategies Used for "Voice."}

In Wave-3 survey, respondents were presented with Afifi and Steuber's (2009) typology of risky revelation strategies and asked if they had used any of those strategies to "voice" over the past two weeks in a yes-no format: preparation and rehearsal (e.g., "I rehearsed the way I would tell my boss the issue with other people first"; $\alpha=.95$ ), directness (e.g., "I discussed the issue with my supervisor in person, face-to-face"; $\alpha=.88$ ); third-party revelations (e.g., "I told someone else who I knew would tell my boss the issue"; $\alpha=.79$ ), incremental disclosures (e.g., "I revealed subtle hints about the issue first to see how my supervisor would respond to it"; $\alpha=.91$ ), "entrapment" (e.g., "I left evidence or information about the issue for my boss to discover"; $\alpha=.85$ ), and indirect mediums (e.g., "I e-mailed my boss about the issue"; $\alpha=.77)$. Reliabilities of the six communication strategies were estimated using the Kuder-Richardson Formula 20 (KR-20), which provides an equivalent to Cronbach's alpha reliability coefficient for dichotomous measures (Cortina, 1993). Those responses were dummy-coded $(1=$ yes; $0=$ no $)$ and the means for each strategy $(\min .=0.00 ; \max .=1.00)$ were computed for subsequent analyses. 


\subsubsection{Covariate}

As a potential covariate, individuals' perceptions of their organization's centralization were assessed using Hage and Aiken's (1969) measure. Example item included "There can be little action here until a supervisor approves a decision" $(\alpha=.90)$.

\section{Results}

\subsection{Measurement Analyses}

To examine the empirical validity of the current study's measures, a confirmatory factor analysis (CFA) was performed using Mplus 4.2 (Muthén \& Muthén, 2006). Items tapping each construct were specified to load onto separate latent variables, which were allowed to correlate freely. This CFA model fit the data reasonably well: $\chi^{2}$ $(754)=1254.9$, RMSEA $=.05, \mathrm{CFI}=.97, \mathrm{SRMR}=.03(\mathrm{Hu} \&$ Bentler, 1999). See Table 1 for the descriptive statistics, bivariate correlations, and reliabilities of the variables concerning the hypotheses and research question.

Table 1. Descriptive Statistics, Bivariate Correlations, and Scale Reliabilities ${ }^{\mathrm{a}}$

\begin{tabular}{|c|c|c|c|c|c|c|c|c|c|c|c|c|c|}
\hline & Variable & 1. & 2. & 3. & 4. & 5. & 6. & 7. & 8. & 9. & 10. & 11. & 12. \\
\hline 1. & LMX & $(.90)$ & & & & & & & & & & & \\
\hline 2. & CB "Voice" & $.24^{*}$ & $(.87)$ & & & & & & & & & & \\
\hline 3. & CB "Silence" & -.04 & $-.20 *$ & $(.88)$ & & & & & & & & & \\
\hline 4. & $\begin{array}{l}\text { Subjective } \\
\text { Norms }\end{array}$ & $.36^{*}$ & $.28^{*}$ & -.08 & $(.85)$ & & & & & & & & \\
\hline 5. & Efficacy & $.51 *$ & $.49^{*}$ & $-.25 *$ & $.30^{*}$ & $(.92)$ & & & & & & & \\
\hline 6. & Intentions & $.39 *$ & $.38^{*}$ & $-.28^{*}$ & $.36^{*}$ & $.42 *$ & $(.90)$ & & & & & & \\
\hline 7. & $\begin{array}{l}\text { Prep \& } \\
\text { Rehearsal }\end{array}$ & $.28 *$ & $.31^{*}$ & $.09^{*}$ & .01 & $.22 *$ & $.14^{*}$ & $(.95)$ & & & & & \\
\hline 8. & Directness & $.21 *$ & $.52 *$ & $-.33 *$ & $.40^{*}$ & $.45^{*}$ & $.41^{*}$ & -.07 & $(.88)$ & & & & \\
\hline 9. & $\begin{array}{l}\text { Third-Party } \\
\text { Revelations }\end{array}$ & .03 & $.19^{*}$ & $-.34 *$ & $.18^{*}$ & $.18^{*}$ & $.23^{*}$ & $-.29 *$ & -.02 & $(.79)$ & & & \\
\hline 10. & $\begin{array}{l}\text { Incremental } \\
\text { Disclosures }\end{array}$ & $.47 *$ & $.52 *$ & -.07 & .07 & $.49 *$ & $.35^{*}$ & $.63^{*}$ & $.15^{*}$ & $-.09 *$ & $(.91)$ & & \\
\hline 11. & "Entrapment" & .05 & $.24^{*}$ & $-.34 *$ & $.17 *$ & $.22 *$ & $.27^{*}$ & $-.13 *$ & -.04 & $.77 *$ & .07 & $(.85)$ & \\
\hline \multirow[t]{3}{*}{12.} & $\begin{array}{l}\text { Indirect } \\
\text { Mediums }\end{array}$ & $.36^{*}$ & $.27 *$ & $-.25 *$ & $.24 *$ & $.47 *$ & $.41^{*}$ & $-.25^{*}$ & $.47^{*}$ & $.33^{*}$ & $.21 *$ & $.30^{*}$ & $(.77)$ \\
\hline & $M$ & 4.42 & 3.95 & 4.00 & 3.59 & 3.95 & 4.13 & 0.35 & 0.29 & 0.20 & 0.25 & 0.40 & 0.13 \\
\hline & $S D$ & 1.46 & 1.70 & 1.35 & 1.57 & 1.63 & 1.25 & 0.18 & 0.23 & 0.22 & 0.28 & 0.24 & 0.13 \\
\hline
\end{tabular}

${ }^{\mathrm{a}} n=539$. Variables 1-5 were measured in Wave-1; variable 6 was measured in Wave-2; and variables 7-12 were measured in Wave-3. $\mathrm{CB}=$ Cost-Benefit Balance. Alpha reliability coefficients are shown on the diagonal in parentheses. LMX, subjective norms, efficacy, and intentions were measured on a Likert-type scale ranging from 1 to 7; cost-benefit balances were assessed on a 7-point semantic-differential scale; six risky revelation strategies used for "voice" were measured in a dichotomous, yes/no (1/0) format and mean scores were used for the analyses.

$* p<.05$

\subsection{Preliminary Analyses}

Prior to the main analyses, preliminary analyses were performed to identify control variables associated with this study's key constructs. For example, MBA-holders perceived more benefit to "voice" than their non-MBA counterparts. Organizational centralization was associated with efficacy, norms, and intentions (Milliken et al., 2003). More information about the results of the preliminary analyses, as well as other details about the current research, is available from the author upon request. Based on the results of those analyses, the decision was made to incorporate 
certain covariates into the model. Specifically, respondents' age and tenure were grand-mean centered and modeled as individual-level covariates; their sex and MBA status were also included. In addition, supervisor's age, sex, and the aggregated score of organizational centralization were modeled as group-level covariates in the main analyses.

Additionally, within-group non-independence of mediator and outcome variables were inspected to examine the appropriateness of applying multi-level analyses (Bliese, 2000). George (1990) suggested that a within-group agreement index, the $r_{\text {wg }}$ statistic (James, Demaree, \& Wolf, 1984), should be greater than .70 to warrant multi-level analyses. Although no specific cutoff exists for ICC(1), James (1982) reported that the median value found in the literature was .12. Finally, Glick (1985) argued that the ICC(2) should be .60 or above. As shown in Table 2, most of this study's mediator and outcome variables showed $r_{\mathrm{wg}}$, ICC(1), and ICC(2) values exceeding those suggested thresholds. Those results suggested that some significant amount of the variance of the constructs highlighted in this study should be accounted for by group-level factors, and thus, modeling a multi-level structure should be warranted (Klein \& Kozlowski, 2000).

Table 2. Within-Group Agreement and Intraclass Correlations (ICCs) for Mediator and Outcome Variables ${ }^{\mathrm{a}}$

\begin{tabular}{lccc}
\hline \multicolumn{1}{c}{ Variable } & $r_{\mathrm{wg}}$ & $\mathrm{ICC}(1)$ & $\mathrm{ICC}(2)$ \\
\hline Cost-Benefit Balance for "Voice" & .84 & .16 & .71 \\
Cost-Benefit Balance for "Silence" & .76 & .13 & .64 \\
Subjective Norms & .84 & .20 & .80 \\
Communication Efficacy & .71 & .11 & .62 \\
Intentions for "Voice" & .85 & .18 & .77 \\
\hline
\end{tabular}

${ }^{a} n=539$. Note. Number of the group-level units (i.e., work groups) was 106, and the group size ranged from three to $10(M=5.1)$.

\subsection{Main Analyses I: An Expanded TPB Model for Employee "Voice" Intentions}

To examine Hypotheses 1 through 4 within a coherent framework, this study employed multi-level structural equation modeling (ML-SEM; Mathieu \& Taylor, 2007; Muthén, 1994), instead of more conventional hierarchical linear modeling (HLM; Raudenbush \& Bryk, 2002; Signer \& Willett, 2003). Both techniques provide appropriate statistical methods to analyze associations among the data with a multi-level structure. HLM, however, accommodates only one individual-level outcome in one model, and hence, testing a mediational model using HLM would require running multiple models and reconfiguring the results by applying mediation testing procedures (Baron \& Kenny, 1986; MacKinnon et al., 2002; Sobel, 1982); addressing this requirement would have unnecessarily complicated the analysis and increased the risk of familywise Type-I error rate inflation (Matsunaga, 2007). In contrast, ML-SEM allows for analyzing complex mediational models, including the one hypothesized in this study (Figure 1). Thus, a series of ML-SEM analyses were run to examine Hypotheses 1 through 4 of this study.

First, an ML-SEM featuring LMX as an exogenous variable, TPB-specified factors (i.e., attitudes, norms, and efficacy) as mediators, and employees' intentions for "voice" as the target variable was tested to examine Hypotheses 1 through 3. Members' age, sex, tenure, and MBA status were also modeled as individual-level covariates, whereas supervisor sex and age, and aggregated score of organizational centralization were included as group-level covariates. This model fit the data acceptably: $\chi^{2}(234)=747.0(p<.01)$, RMSEA $=.06$, CFI $=.97$, SRMR Within $=.02$, SRMR Between $=.01$ (see Table 3 for the summary of parameter estimates).

The results mostly supported this study's hypotheses. Specifically, the more benefit (and the less cost) individuals perceived regarding "voice," the stronger their intentions $(\beta=.10, p=.02)$; similarly, those who felt colleagues would support their "voicing" tended to indicate stronger intentions $(\beta=.25, p<.01)$. At the same time, the link between communication efficacy and intentions was not significant $(\beta=-.06, p=.16)$. Thus, Hypothesis 1 was only partially supported. Additionally, consistent with Hypothesis 2, the cost-benefit balance for "silence" was found to have a unique significant effect on intentions $(\beta=-.20, p<.01)$, after controlling for the effects of the cost-benefit balance for "voice." Thus, Hypothesis 2 was supported. 
Table 3. Robust Maximum-Likelihood Estimates for the Expanded TPB Model of Employee "Voice" Intentions

\begin{tabular}{|c|c|c|c|c|c|c|c|c|c|c|}
\hline \multirow[b]{3}{*}{ Predictor } & \multicolumn{10}{|c|}{ Target Variable } \\
\hline & \multicolumn{2}{|c|}{ Intentions } & \multicolumn{2}{|c|}{ CB "Voice" } & \multicolumn{2}{|c|}{ CB "Silence" } & \multicolumn{2}{|c|}{ Norms } & \multicolumn{2}{|c|}{ Efficacy } \\
\hline & H1-H3 & $\mathrm{H} 4$ & $\overline{\mathrm{H} 1-\mathrm{H} 3}$ & $\mathrm{H} 4$ & 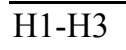 & $\mathrm{H} 4$ & H1-H3 & H4 & $\overline{\mathrm{H} 1-\mathrm{H} 3}$ & $\mathrm{H} 4$ \\
\hline \multicolumn{11}{|l|}{ Group Level } \\
\hline $\begin{array}{l}\text { LMX } \\
\text { Differentiation }\end{array}$ & & $-.47 *$ & & $-.47^{*}$ & & $.25^{*}$ & & $-.30 *$ & & $-.30 *$ \\
\hline \multicolumn{11}{|l|}{ Individual Level } \\
\hline LMX & .03 & .02 & $.45^{*}$ & $.45^{*}$ & $-.33 *$ & $-.34 *$ & $.25^{*}$ & $.25^{*}$ & .08 & .08 \\
\hline CB “Voice" & $.10^{*}$ & $.11^{*}$ & & & & & & & & \\
\hline CB "Silence" & $-.20 *$ & $-.20 *$ & & & & & & & & \\
\hline $\begin{array}{l}\text { Subjective } \\
\text { Norms }\end{array}$ & $.25^{*}$ & $.25^{*}$ & & & & & & & & \\
\hline Efficacy & -.06 & -.06 & & & & & & & & \\
\hline Model $R_{\text {Within }}^{2}$ & .11 & .12 & .20 & .20 & . 11 & .12 & .06 & .06 & .01 & .01 \\
\hline$\Delta R_{\text {Within }}^{2}$ & & .01 & & .00 & & .01 & & .00 & & .00 \\
\hline Model $R_{\text {Between }}^{2}$ & .17 & .39 & .24 & .46 & .16 & .23 & .32 & .42 & .33 & .43 \\
\hline$\Delta R_{\text {Between }}^{2}$ & & .22 & & .22 & & .06 & & .09 & & .09 \\
\hline
\end{tabular}

${ }^{a} n=539$. Note. CB "Voice" = Cost-Benefit Balance for "Voice." CB "Silence" = Cost-Benefit Balance for "Silence." Efficacy $=$ Communication Efficacy. All parameter estimates are completely standardized. Parameter estimates of covariates are not shown in the table (details regarding the covariates' effects are available from the author upon request).

$* p<.05$

Concerning Hypothesis 3, individual-level LMX quality was statistically significantly associated with employees' perceptions of the cost-benefit balance for "voice" $(\beta=.45, p<.01)$, cost-benefit balance for "silence" $(\beta=-.33, p$ $<.01)$, and subjective norms $(\beta=.25, p<.01)$. The association between LMX quality and one's communication efficacy was, however, not statistically significant $(\beta=.08, p=.07)$. Further, analyses of the indirect effects suggested that perceived LMX quality was statistically significantly associated with individuals' "voice" intentions via those TPB-specified psychological factors (except for communication efficacy); the standardized indirect effect of LMX on intentions was $.17(p<.01)$. Thus, Hypothesis 3 was supported, except for the parts concerning individuals' communication efficacy. Overall, this model accounted for $11 \%$ of the within-group variance of employee "voice" intentions.

To test Hypothesis 4, another model was constructed by adding LMX differentiation as a predictor at the group level. This model showed an acceptable fit to the data: $\chi^{2}(318)=980.1(p<.01)$, RMSEA $=.06$, CFI $=.98$, SRMR Within $_{\text {, }}$ $=.02, \mathrm{SRMR}_{\text {Between }}=.01$. The results indicated that, after accounting for the effects of individual-level predictors, LMX differentiation had significant negative effect on employees' perceptions of the cost-benefit balance for "voice" behaviors $(\beta=-.47, p<.01)$. On the other hand, LMX differentiation was associated with greater perceived benefit for "silence" ( $\beta=.25, p<.01)$. In addition, LMX differentiation was negatively associated with subjective norms ( $\beta$ $=-.30, p<.01)$ and communication efficacy $(\beta=-.30, p<.01)$. Finally, LMX differentiation had a significant direct effect on employee "voice" intentions such that, the greater the LMX differentiation, the weaker employees" intentions to engage in "voice" behaviors $(\beta=-.47, p<.01)$. Controlling for the effects of covariates such as the given work unit's organizational centralization level or supervisor's age and sex, LMX differentiation accounted for additional $22 \%$ of the group-level variance of employee "voice" intentions (i.e., $\Delta R^{2}{ }_{\text {Between }}=.22$ ). Overall, those results supported Hypothesis 4 of this study.

\subsection{Main Analyses II: "Voice” Strategy Patterns and Their Predictors}

This study posed a research question on employees" "voice" strategy use. Because most of the existing studies have focused on the issue of frequency (i.e., whether employees "voice" or not), few empirical findings are available 
regarding this issue of strategy use patterns (Morrison et al., 2011). In addition, it was expected that individuals would utilize multiple strategies in a variety of combinations - for example, employees might rehearse how they would "voice" with coworkers first and eventually speak up to the supervisor, and also follow up on the discussion via e-mails. To capture such uncharted complexity, an exploratory approach was needed.

Toward this end, the current study employed a statistical method called latent profile analysis (LPA; Gibson, 1959; Muthén, 2002; Vermunt \& Magidson, 2002) using Mplus 4.2. LPA takes continuous observed variables to estimate a categorical latent variable; in this study's case, individual scores for Afifi and Steuber's (2009) six risky revelation strategies were used to model a categorical latent construct representing major "voicing" strategy use patterns. As such, LPA is similar to traditional methods such as cluster analysis (Kaufman \& Rousseeuw, 1990) and multidimensional scaling (MDS; Kruskal, 1964). LPA, however, has a number of advantages (Vermunt \& Magidson, 2002). First, LPA hypothesizes a conceptual model a priori and its goodness-of-fit can be evaluated statistically. Thus, determination of the number of latent profiles is less arbitrary than eyeball-inspection of a dendrogram used in cluster analysis, for example. Second, LPA controls for data unreliability by modeling the measurement and latent structural parts separately. Finally, LPA models can be estimated using the robust maximum likelihood method, which provides asymptotically robust estimates against sampling error and also yields unbiased estimates while accommodating missing data (Gerbing \& Anderson, 1985).

First, an LPA model without any predictor was run to determine the number of latent categories to adequately reconstruct the variety and quality of employee "voice" strategy use. In LPA, such determination is made by comparing of models that specify a different number of latent categories based on the same set of observed variables (Vermunt \& Magidson, 2002). Those models are compared on statistical and theoretical grounds. Statistically, this study used: (a) the Bayesian information criterion (BIC; the smaller BIC, the better the model fit); (b) entropy, which indicates the accuracy of profile classification, and conventionally, a value higher than .80 is considered acceptable; and (c) the Lo-Mendell-Rubin test, which tests if adding a new latent category improves the model fit (Lo, Mendell, \& Rubin, 2001). Theoretically, model interpretability provides an important evaluation criterion such that all extracted latent categories should be clearly distinguishable from one another in terms of their parameter estimates.

Examination of a series of LPA models indicated that a 5-profile model would provide the most adequate approximation for this study's data. As shown in Table 4, the BIC value associated with the 5-profile model was noticeably lower than its preceding models (e.g., $\Delta \mathrm{BIC}_{4 \text {-profile } \rightarrow \text {-profile }}=1155.9$ ), whereas the differences between the 5 -profile model and the models with more profiles in BIC were miniscule. The 5-profile model's entropy value well-exceeded the .80 threshold (entropy 5 -profile $=.92$ ). Further, the results of the Lo-Mendell-Rubin test indicated that modeling the fifth profile significantly improved the fit $\left(\operatorname{LMR}_{5 \text {-profile }}=656.9, p<.01\right)$; on the other hand, the goodness-of-fit improvement by adding a sixth profile to the model was not statistically significant $\left(\mathrm{LMR}_{6 \text {-profile }}=\right.$ 28.2, $p=.21$ ). Finally, all profiles extracted in the 5-profile model demonstrated clearly distinguishable characteristics, which are described below.

Table 4. Comparison of the Latent Profile Analysis Models for Employee "Voice" Strategy Use

\begin{tabular}{lrrrrrr}
\hline \multicolumn{1}{c}{ Model } & \multicolumn{1}{c}{$G$} & $k$ & \multicolumn{1}{c}{ BIC } & \multicolumn{1}{c}{$\Delta$ BIC } & \multicolumn{1}{c}{ Entropy } & \multicolumn{1}{c}{ LMR } \\
\hline 2-Profile & -3022.7 & 19 & 6097.3 & NA & 1.00 & $1471.8^{*}$ \\
3-Profile & -2737.7 & 26 & 5546.4 & 550.9 & .98 & $896.5^{*}$ \\
4-Profile & -2594.2 & 33 & 5278.5 & 267.9 & .97 & $300.2^{*}$ \\
5-Profile & -2006.7 & 40 & 4122.7 & 1155.9 & .92 & $656.9^{*}$ \\
6-Profile & -1996.9 & 47 & 4122.2 & 0.5 & .82 & 28.2 \\
7-Profile & -1982.3 & 54 & 4112.1 & 10.1 & .77 & 22.2 \\
8-Profile & -1970.8 & 61 & 4108.2 & 3.9 & .74 & 14.6 \\
\hline
\end{tabular}

${ }^{a} n=539$. Note. $G=$ Log likelihood. $k=$ the number of freely estimated parameters. BIC $=$ the Bayesian Information Criterion. LMR $=$ Lo-Mendell-Rubin test statistic.

$* p<.05$ 
The first profile, Direct, showed a strong inclination to use the "directness" strategy (i.e., "voicing" in the face-to-face settings) and weak tendencies to use the other strategies. A second profile was labeled as Deniable, because of its characteristic proclivity to use strategies with high deniability (i.e., "third-party revelations" and "entrapment"). Third, the Careful profile was distinguished by its strong tendencies to use "incremental disclosure" and "preparation \& rehearsal," two strategies that would allow employees to make little steps to test the water before engaging in the "voice" behavior with their supervisor as the target. Individuals identified with a fourth profile, Multichannel, were unique in that they tended to use a variety of strategies; also, they are the only group who would willingly use the "indirect mediums" strategy. Finally, nearly half of the respondents $(n=250)$ were classified as Undisclosed, because they did not show inclination to engage in "voice" behaviors (see Table 5 for the summary of parameter estimates).

Table 5. Parameter Estimates of the Latent Profiles for Employee "Voice" Strategy Use

\begin{tabular}{|c|c|c|c|c|c|}
\hline \multirow[b]{2}{*}{ Parameter } & \multicolumn{5}{|c|}{ Latent Profile } \\
\hline & Direct & Deniable & Careful & Multichannel & Undisclosed \\
\hline \multicolumn{6}{|l|}{ Strategy Use } \\
\hline Directness & .796 & .182 & .252 & .528 & .181 \\
\hline Incremental Disclosure & .219 & .091 & .807 & .394 & .076 \\
\hline Preparation \& Rehearsal & .345 & .289 & .689 & .155 & .288 \\
\hline Third-Party Revelations & .069 & .574 & .092 & .510 & .072 \\
\hline "Entrapment" & .213 & .771 & .386 & .728 & .251 \\
\hline Indirect Mediums & .175 & .075 & .100 & .527 & .076 \\
\hline \multicolumn{6}{|l|}{ Frequency } \\
\hline$n$ & 56 & 96 & 93 & 44 & 250 \\
\hline Percentage & 10.4 & 17.8 & 17.3 & 8.2 & 46.4 \\
\hline
\end{tabular}

Next, predictor variables and covariates were added to this 5-profile model. All parameters were estimated using the Undisclosed latent profile as the baseline (i.e., reference) category. The results indicated that employees' "voice" strategy use was strongly associated with their intentions and TPB-specified psychological factors, whereas relational and contextual elements (i.e., perceived LMX quality and group-level LMX differentiation) also showed some hints of influences (see Table 6 for the summary of parameter estimates).

Intentions had positive effects on "voicing" profiles: For the Direct profile, $\beta=.20$, Odds Ratio $(\mathrm{OR})=5.47, p<.01$; for Deniable, $\beta=.23, \mathrm{OR}=6.09, p<.01$; for Careful, $\beta=.12$, OR = 3.55, $p=.04$; and for Multichannel, $\beta=.24$, OR $=10.08, p<.01$. That is, the higher the intentions, the more likely employees would take one of those "voicing" strategies, instead of the Undisclosed. For example, individuals who scored one unit higher in intentions than the average would be approximately 5.5 times more likely to take the Direct approach (i.e., "voicing" in face-to-face settings) than being classified with the Undisclosed approach.

Most TPB-specified factors also were associated with the "voice" strategy profiles (see Table 6). Cost-benefit balance for "voice" had positive effects ( $\beta$ s ranging from .28 to .39 , ORs ranging from 8.68 to 20.01). In contrast, cost-benefit balance for "silence" had negative effects on the Direct $(\beta=-.12, \mathrm{OR}=0.12, p=.03)$, Careful $(\beta=-.16$, $\mathrm{OR}=0.09, p<.01)$, and Multichannel profiles $(\beta=-.17, \mathrm{OR}=0.04, p<.01)$, but the link between the cost-benefit balance for "silence" and the Deniable profile was not significant $(\beta=.02, \mathrm{OR}=1.29, p=.28)$. Interestingly, subjective norms' effects were significant only for Direct $(\beta=.13$, OR $=4.71, p<.01)$ and Multichannel $(\beta=.07$, $\mathrm{OR}=2.46, p=.05)$. The effects of communication efficacy were statistically significant, except for the Deniable profile $(\beta=.04, \mathrm{OR}=1.78, p=.15)$. 
Table 6. Parameter Estimates of the Predictors for the Employee "Voice" Strategy Use

\begin{tabular}{|c|c|c|c|c|c|c|c|c|}
\hline \multirow[b]{3}{*}{ Predictor } & \multicolumn{8}{|c|}{ Latent Profile } \\
\hline & \multicolumn{2}{|c|}{$\begin{array}{c}\text { Direct } \\
(n=56)\end{array}$} & \multicolumn{2}{|c|}{$\begin{array}{c}\text { Deniable } \\
(n=96)\end{array}$} & \multicolumn{2}{|c|}{$\begin{array}{l}\text { Careful } \\
(n=93)\end{array}$} & \multicolumn{2}{|c|}{$\begin{array}{c}\text { Multichannel } \\
\quad(n=44)\end{array}$} \\
\hline & $\beta$ & OR & $\beta$ & OR & $\beta$ & OR & $\beta$ & OR \\
\hline \multicolumn{9}{|l|}{ Group-Level } \\
\hline $\begin{array}{l}\text { LMX } \\
\text { Differentiation }\end{array}$ & -.09 & $0.03 * *$ & .14 & $15.60 * *$ & .02 & 1.31 & .01 & 1.08 \\
\hline \multicolumn{9}{|l|}{ Individual-Level } \\
\hline $\begin{array}{l}\text { Perceived LMX } \\
\text { Quality }\end{array}$ & .27 & $7.39 * *$ & .13 & $3.89^{*}$ & .30 & $10.98 * *$ & .19 & $5.62 * *$ \\
\hline $\begin{array}{l}\text { Cost-Benefit } \\
\text { Balance for } \\
\text { "Voice" }\end{array}$ & .33 & $12.74 * *$ & .28 & $8.68 * *$ & .39 & $20.01 * *$ & .37 & $18.98 * *$ \\
\hline $\begin{array}{l}\text { Cost-Benefit } \\
\text { Balance for } \\
\text { "Silence" }\end{array}$ & -.12 & $0.12 *$ & .02 & 1.29 & -.16 & $0.09 * *$ & -.17 & $0.04 * *$ \\
\hline Subjective Norms & .13 & $4.71^{* *}$ & .06 & 2.23 & .04 & 1.77 & .07 & $2.46^{*}$ \\
\hline $\begin{array}{l}\text { Communication } \\
\text { Efficacy }\end{array}$ & .12 & $4.01^{*}$ & .04 & 1.78 & .13 & $3.94 * *$ & .24 & $9.56^{* *}$ \\
\hline Intentions & .20 & $5.47 * *$ & .23 & $6.09 * *$ & .12 & $3.55^{*}$ & .24 & $10.08^{* *}$ \\
\hline
\end{tabular}

${ }^{\mathrm{a}} n=539$. Note. $\beta=$ Completed standardized pseudo-multinomial-regression coefficient. OR $=$ Odds Ratio. All parameters were estimated using the "Undisclosed" latent profile $(n=250)$ as the baseline category. Parameter estimates of covariates are not shown in the table, and the details are available from the author upon request.

$* p<.05 \quad * * p<.01$

Finally, the results indicated that, after controlling for the effects of covariates and TPB-specified factors, perceived LMX quality and group-level LMX differentiation showed significant associations with the "voicing" profiles. LMX quality had positive effects such that, the more positive the perceived LMX quality, the more likely individuals would take "voicing" strategy ( $\beta$ s ranging from .13 to .30 , ORs ranging from 3.89 to 10.98). In addition, LMX differentiation had two contrasting effects: For the Direct profile, $\beta=-.09, \mathrm{OR}=0.03, p<.01$; and for the Deniable profile, $\beta=.14$, OR $=15.60, p<.01$. The effects of LMX differentiation on the Careful or Multichannel profile were not statistically significant.

\section{Discussion}

This study contributes to the growing body of literature on employee "voice" (Brinsfield et al., 2009). As expected by TPB (Ajzen, 1991) and related theories, organizational members' intentions for "voice" were associated with their attitudes, efficacy, and perceptions about their surrounding environment, such as subjective norms and LMX. Further, those psychological and relational factors helped predict major patterns of their "voice" strategy use. Those findings bring both theoretical and practical implications, which are explored in turn below.

\subsection{Theoretical Implications}

One of this study's primary theoretical contributions is the identification of TPB as a useful framework to analyze employee "voice." TPB posits that decision-making involves complex psychological processing (Ajzen, 1991). Consistent with this notion of multi-factor dynamics, perceptions about cost-benefit balances and subjective norms (but not efficacy) showed significant associations with employees' "voice" intentions and behaviors. Further, a review of the literature indicated that considerations over not "voicing"-or silence-would provide a distinct determinant vis-à-vis those over "voicing" (McGraw et al., 2010; O'Keefe, 2002). The current study's results supported this surmise, as the cost-benefit balance for "silence" had unique effects even after controlling for the 
effects of the cost-benefit balance for "voice." This finding is notable because it expands the scope of TPB and thereby adds to its explanatory power.

As a second major finding, this study has revealed that individuals make decisions not only based on logical considerations over cost-benefit balances but also by drawing on subjectively construed norms. That is, the results of ML-SEM and LPA analyses indicated that subjective norms provide a strong predictor of employee "voice" intentions and strategy use (Tables $3 \& 6$ ). It should be stressed that this finding signifies a distinct paradigm centering upon one's social network, rather than simply identifying a new predictor variable.

Unlike the social-exchange perspective that regards individuals as rational agents that seek to maximize rewards and minimize risks, TPB recognizes human bounded rationality as integral to decision-making processes (Gigerenzer \& Goldstein, 1996; Simon, 1991). According to TPB, individuals are influenced by what they think is preferred by others, and such social influences can override the effects of logical reasoning (Rimal \& Real, 2005). Stated differently, individuals might engage in a behavior that might not be logically sensible for them if they think that behavior is considered normative or expected by others, and vice versa. This tenet of TPB found support in the current study, which suggests that employee "voice" is an inherently social phenomenon.

As the final theoretical contribution, this study has established an initial typology of "voice" strategy use and its correlates. LPA analyses extracted five distinct profiles, which represent major behavioral patterns of employee "voice" (or lack thereof). As Morrison et al. (2011) pointed out, existing studies almost exclusively focus on frequency (i.e., whether employees "voice" or not), but little is known about how individuals actually express their ideas and opinions. The current findings help address this limitation in the literature by providing empirical evidence of qualitatively distinct patterns of employees" "voice" strategy use.

The five profiles identified in this study (Table 5) suggest that discussing the employee "voice" phenomenon in terms of frequency alone is a gross oversimplification. That is, individuals fitting the conventional notion of "voicing"-Direct or Multichannel—only amounted to about 18\% of this study's sample. On the other hand, $35 \%$ showed highly indirect patterns, namely Deniable and Careful; they probably would not be deemed as part of the "voicing" population by convention, because research has implicitly regarded direct, face-to-face expressions as a primary form of "voice" behavior (Van Dyne \& LePine, 1998). This study's findings provide an initial set of empirical evidence to overcome such overgeneralization and analyze the rich complexity of employee "voice" phenomena with greater precision.

\subsection{Practical Implications}

In addition to the theoretical contributions, this study's findings provide a number of practical implications. First, to deal with "voice" dynamics effectively, leaders need to attend the within-group norms and relationships from members' perspective. As noted earlier, members seem to base their "voice" decisions not only on what is logically expedient or beneficial for them but also on heuristic considerations, namely subjective norms and LMX perceptions. This notion per se should come as no surprise, because previous TPB research has demonstrated that subjective norms provide a powerful determinant, and LMX has been found to affect employee "voice" through individual- and group-level dynamics. At the same time, the current findings do point to the limitation of social-exchange approaches that capitalize on individuals' risk-versus-reward reckoning (e.g., Kish-Gephart et al., 2009). This study's results suggest that there could be cases where employees enact a behavior that does not contribute or even runs counter to their personal benefit. It therefore seems reasonable to posit that trumpeting the benefit of "voice" alone is not sufficient to solicit members to open up and share their opinions. Rather, emphasizing their centrality within the group's social network and/or work flow, appealing to their self-esteem, and encouraging them to stand on behalf of the colleagues may be more effective, especially for those who play central roles within the group.

Second, managers should be mindful about relational climate surrounding themselves and organizational members, as LMX perceptions turned out to provide two of the strongest predictors of employee "voice" intentions and strategy use (Tables $3 \& 6$ ). Specifically, the more positive the LMX quality and the smaller the LMX differentiation, the more likely employees intend and enact "voice" behaviors. Thus, if managers seek to promote upward communication through relational approaches, they should strive to maintain positive relationships with group members and also minimize the within-group LMX differentiation level at the same time.

Third, true opinion leaders may be different from those who stand up and share ideas directly with supervisors. The LPA results (Table 5) indicate that a considerable number of individuals - particularly those classified with the Deniable profile (who constituted $17.8 \%$ of the current sample) - use "third-party revelations" as one of their primary strategies. Those individuals would not actively engage in direct upward communication. Instead, they 
reveal their "voice" to coworkers, who they think will eventually convey the revealed ideas to the supervisor. Thus, identifying only those who directly communicate with leaders as opinion leaders may result in miscomprehension of the members' capabilities and contributions.

Fourth, as far as employee "voice" is concerned, managers should not expect much from computer-mediated communication (CMC). The LPA results showed that only those who were classified with the Multichannel profile used "indirect mediums." Put differently, communicating one's "voice" via digital media, such as e-mail, seems the last choice for employees. This in fact is unsurprising because "voice" is a risky behavior (Detert \& Burris, 2007; Detert \& Edmondson, 2011), and thus, it is imprudent for organizational members to use digital media that leave easily identifiable traces. Thus, leaders seeking employee "voice" should not rely on CMC. Instead, they should arrange communication channels so that members can safely reveal their opinions.

\subsection{Limitations \& Future Directions}

Finally, limitations of this study and directions for future research are discussed below. First, collecting data from only one source (i.e., employees) is a major limitation, since it raises the concern over the common-method-variance bias (Podsakoff, MacKenzie, Lee, \& Podsakoff, 2003). Future research should address this limitation by obtaining data from multiple sources, including one's colleagues and supervisors. At the same time, the longitudinal data collected through the 3-wave design should be noted as one of the strengths of the current research, as it provided a methodological warrant to specify the mediational model tested in this study.

Second, this study collected data from Japan, which is known for its strong collectivism and vertical orientation (Hofstede, 2001; Oetzel et al., 2001), and how such cultural tendencies affected the current findings has yet to be examined. It should be noted, however, that this study's hypotheses were formulated based on the existing literature, the majority of which consists of studies conducted in Western countries; and yet, the results of this study are mostly consistent with the patterns expected from those previous findings. Thus, it seems reasonable to contend that the current findings should hold at least some degree of generalizability. Third, this study did not examine how social dynamics affect "voice." Research suggests, for example, that subjective norms are more influential when employees have close relationships with colleagues (Blader \& Tyler, 2009; Janssen \& Huang, 2008). To scrutinize those social influences, future studies should incorporate relational constructs such as team-member exchange (Seers, 1989).

Fourth, future research should explore individual differences that are relevant to "voice" behavior. For instance, individuals with strong other-orientation tendency are likely to make decisions heuristically and behave in the way that they think others will approve, even if it is inconsistent with their own attitudes (Meglino \& Korsgaard, 2004). Finally, although this study has explored how organizational members "voice," the issue of what they typically "voice" has been left unexamined and researchers of future studies should explore it (Morrison et al., 2011).

\subsection{Conclusion}

Years of research notwithstanding, the governing mechanism of employee "voice" is still to be seen. Utilizing TPB as a framework, this study has integrated a number of individual- and group-level predictors of "voice" behavior, explored the psychological structure underlying individuals' decision-making, and established an initial typology of employee "voice" strategy use. Future research should draw on those toeholds gained in this study and explore the psychological, relational, and communicative dynamics undergirding the "voice" phenomenon.

\section{References}

Afifi, T., \& Steuber, K. (2009). The revelation risk model (RRM): Factors that predict the revelation of secrets and the strategies used to reveal them. Communication Monographs, 76, 144-176. http://dx.doi.org/https://doi.org/10.1080/03637750902828412

Afifi, W. A., \& Caughlin, J. P. (2006). A close look at revealing secrets and some consequences that follow. Communication Research, 33, 467-488. http://dx.doi.org/10.1177/0093650206293250

Ajzen, I. (1991). The theory of planned behavior. Organizational Behavior and Human Decision Processes, 50, 179-211. http://dx.doi.org/10.1016/0749-5978(91)90020-T

Ajzen, I., \& Madden, T. J. (1986). Prediction of goal-directed behavior: Attitudes, intentions, and perceived behavioral control. Journal of Experimental Social Psychology, 22, 453-474. http://dx.doi.org/10.1016/0022-1031(86)90045-4

Anand, S., Vidyarthi, P. R., Liden, R. C., \& Rousseau, D. M. (2010). Good citizens in poor-quality relationships: 
Idiosyncratic deals as a substitute for relationship quality. Academy of Management Journal, 53, 970-988. http://dx.doi.org/10.5465/AMJ.2010.54533176

Aryee, S., Budhwar, P. S., \& Chen, Z. X. (2002). Trust as a mediator of the relationship between organizational justice and work outcomes: Test of a social exchange model. Journal of Organizational Behavior, 23, 267-285. http://dx.doi.org/10.1002/job.138

Ashford, S. J., Sutcliffe, K. M., \& Christianson, M. K. (2009). Speaking up and speaking out: The leadership dynamics of voice in organizations. In J. Greenberg \& M. J. Edwards (Eds.), Voice and silence in organizations (pp. 175-202). Bingley, UK: Emerald Group.

Bandura, A. (1997). Self-efficacy: The exercise of control. New York: Freeman.

Baron, R. M., \& Kenny, D. A. (1986). The moderator-mediator variable distinction in social psychological research: Conceptual, strategic, and statistical considerations. Journal of Personality and Social Psychology, 51, 1173-1182. http://dx.doi.org/10.1037/0022-3514.51.6.1173

Berger, C. R. (1997). Planning strategic interaction: Attaining goals through communicative action. Hillsdale, NJ: LEA.

Blader, S. L., \& Tyler, T. R. (2009). Testing and extending the group engagement model: Linkages between social identity, procedural justice, economic outcomes, and extrarole behavior. Journal of Applied Psychology, 94, 445-464. http://dx.doi.org/10.1037/a0013935

Bliese, P. D. (2000). Within-group agreement, non-independence, and reliability: Implications for data aggregation and analysis. In K. J. Klein \& S. W. Kozlowski (Eds.), Multilevel theory, research and methods in organizations (pp. 349-381). San Francisco: Jossy-Bass.

Brinsfield, C. T., Edwards, M. J., \& Greenberg, J. (2009). Voice and silence in organizations: Historical review and current conceptualizations. In J. Greenberg \& M. J. Edwards (Eds.), Voice and silence in organizations (pp. 3-36). Bingley, UK: Emerald Group.

Brislin, R. W. (1970). Back-translation for cross-cultural research. Journal of Cross-Cultural Psychology, 1, 185-216. http://dx.doi.org/10.1177/135910457000100301

Brockner, J., Ackerman, G., Greenberg, J., Gelfand, M. J., Franecsco, A. M., Chen, Z. X., et al. (2001). Culture and procedural justice: The influence of power distance on reactions to voice. Journal of Experimental Social Psychology, 37, 300-315. http://dx.doi.org/10.1006/jesp.2000.1451

Burris, E. R., Detert, J. R., \& Chiaburu, D. S. (2008). Quitting before leaving: The mediating effects of psychological attachment and detachment on voice. Journal of Applied Psychology, 93, 912-922. http://dx.doi.org/10.1037/0021-9010.93.4.912

Cortina, J. M. (1993). What is coefficient alpha? An examination of theory and applications. Journal of Applied Psychology, 78, 98-104. http://dx.doi.org/10.1037/0021-9010.78.1.98

Davis, L. E., Ajzen, I., Saunders, J., \& Williams, T. (2002). The decision of African American students to complete high school: An application of the theory of planned behavior. Journal of Educational Psychology, 94, 810-819. http://dx.doi.org/10.1037/0022-0663.94.4.810

Detert, J. R., \& Burris, E. R. (2007). Leadership behavior and employee voice: Is the door really open? Academy of Management Journal, 50, 869-884. http://dx.doi.org/10.5465/AMJ.2007.26279183

Detert, J. R., \& Edmondson, A. C. (2011). Implicit voice theories: Taken-for-granted rules of self-censorship at work. Academy of Management Journal, 54, 461-488. http://dx.doi.org/10.5465/AMJ.2011.61967925

Dienesch, R. M., \& Liden, R. M. (1986). Leader-member exchange model of leadership: A critique and further development. Academy of Management Review, 11, 618-634. http://dx.doi.org/10.5465/AMR.1986.4306242

Edgar, T. (1994). Self-disclosure behaviors in the stigmatized: Strategies and outcomes for the revelation of sexual orientation. In J. Ringer (Ed.), Queer words, queer images: Communication and construction of homosexuality (pp. 21-39). New York: NYU Press.

Edmondson, A. C. (2003). Speaking up in the operating room: How team leaders promote learning in interdisciplinary teams. Journal of Management Studies, 40, 1419-1452. http://dx.doi.org/10.1111/1467-6486.00386

Erdogan, B., \& Bauer, T. N. (2010). Differentiated leader-member exchanges: The buffering role of justice climate. 
Journal of Applied Psychology, 95, 1104-1120. http://dx.doi.org/10.1037/a0020578

Erdogan, B., Kraimer, M. L., \& Liden, R. C. (2004). Work value congruence and intrinsic career success: The compensatory roles of leader-member exchange and perceived organizational support. Personnel Psychology, 57, 305-332. http://dx.doi.org/10.1111/j.1744-6570.2004.tb02493.x

Fishbein, M., \& Ajzen, I. (2010). Predicting and changing behavior: The reasoned action approach. New York: Psychology Press.

Frattaroli, J. (2006). Experimental disclosure and its moderators: A meta-analysis. Psychological Bulletin, 132, 823-865. http://dx.doi.org/10.1037/0033-2909.132.6.823

George, J. M. (1990). Personality, affect, and behavior in groups. Journal of Applied Psychology, 75, 107-116. http://dx.doi.org/10.1037/0021-9010.75.2.107

Gerbing, D. W., \& Anderson, J. C. (1985). The effects of sampling error and model characteristics on parameter estimation for maximum likelihood confirmatory factor analysis. Multivariate Behavioral Research, 20, 255-271. http://dx.doi.org/10.1207/s15327906mbr2003_2

Gerstner, C. R., \& Day, D. V. (1997). Meta-analytic review of leader-member exchange theory: Correlates and construct issues. Journal of Applied Psychology, 82, 827-844. http://dx.doi.org/10.1037/0021-9010.82.6.827

Gibson, W. A. (1959). Three multivariate models: Factor analysis, latent structure analysis, and latent profile analysis. Psychometrika, 24, 229-252. http://dx.doi.org/10.1007/BF02289845

Gigerenzer, G., \& Goldstein, D. G. (1996). Reasoning the fast and frugal way: Models of bounded rationality. Psychological Review, 103, 650-669. http://dx.doi.org/10.1037/0033-295X.103.4.650

Glick, W. H. (1985). Conceptualizing and measuring organizational and psychological climate: Pitfalls in multilevel research. Academy of Management Review, 10, 601-616. http://dx.doi.org/10.5465/AMR.1985.4279045

Guo, Q., Johnson, C. A., Unger, J. B., Lee, L., Xie, B., Chou, C.-P., et al. (2006). Utility of the theory of reasoned action and theory of planned behavior for predicting Chinese adolescent smoking. Addictive Behaviors, 32, 1066-1081. http://dx.doi.org/10.1016/j.addbeh.2006.07.015

Hage, J., \& Aiken, M. (1969). Routine technology, social structure, and organizational goals. Administrative Science Quarterly, 14, 366-376. http://dx.doi.org/10.2307/2391132

Harlos, K. P. (2001). When organizational voice systems fail. Journal of Applied Behavioral Science, 37, 324-342. http://dx.doi.org/10.1177/0021886301373005

Henderson, D. J., Liden, R. C., Glibkowski, B. C., \& Chaudhry, A. (2009). LMX differentiation: A multilevel review and examination of its antecedents and outcomes. Leadership Quarterly, 20, 517-534. http://dx.doi.org/10.1016/j.leaqua.2009.04.003

Hooper, D. T., \& Martin, R. (2008). Beyond personal leader-member exchange (LMX) quality: The effects of perceived LMX variability on employee reactions. Leadership Quarterly, 19, 20-30. http://dx.doi.org/10.1016/j.leaqua.2007.12.002

Hu, L., \& Bentler, P. M. (1999). Cutoff criteria for fit indexes in covariance structure analysis: Conventional criteria versus new alternatives. Structural Equation Modeling, 6, 1-55. http://dx.doi.org/10.1080/10705519909540118

James, L. R. (1982). Aggregation bias in estimates of perceptional agreement. Journal of Applied Psychology, 67, 219-229. http://dx.doi.org/10.1037/0021-9010.67.2.219

James, L. R., Demaree, R. G., \& Wolf, G. (1984). Estimating within-group interrater reliability with and without response bias. Journal of Applied Psychology, 69, 85-98. http://dx.doi.org/10.1037/0021-9010.69.1.85

James, L. R., James, L. A., \& Ashe, D. K. (1990). The meaning of organizations: The role of cognition and values. In B. Schneider (Ed.), Organizational climate and culture (pp. 40-84). San Francisco: Jossey-Bass.

Janssen, O., \& Huang, X. (2008). Us and me: Team identification and individual differentiation as complementary drivers of team members' citizenship and creative behaviors. Journal of Management, 34, 69-88. http://dx.doi.org/10.1177/0149206307309263

Kacmar, K. M., Witt, L. A., Zivnuska, S., \& Gully, S. M. (2003). The interactive effect of leader-member exchange and communication frequency on performance ratings. Journal of Applied Psychology, 88, 764-772. http://dx.doi.org/10.1037/0021-9010.88.4.764 
Kaufman, L., \& Rousseeuw, P. J. (1990). Finding groups in data: An introduction to cluster analysis. New York: Wiley.

Kermer, D. A., Driver-Linn, E., Wilson, T. D., \& Gilbert, D. T. (2006). Loss aversion is an affective forecasting error. Psychological Science, 17, 649-653. http://dx.doi.org/10.1111/j.1467-9280.2006.01760.x

Kish-Gephart, J., Detert, J. R., Trevino, L. K., \& Edmondson, A. C. (2009). Silenced by fear: Psychological, social, and evolutionary drivers of voice behavior at work. In B. M. Staw \& A. P. Brief (Eds.), Research in organizational behavior (vol. 29, pp.163-193). Greenwich, CT: JAI.

Klein, K. J., \& Kozlowski, S. W. J. (2000). From micro to meso: Critical steps in conceptualizing and conducting multilevel research. Organizational Research Methods, 3, 211-236. http://dx.doi.org/10.1177/109442810033001

Kruskal, J. B. (1964). Multidimensional scaling by optimizing goodness of fit to a nonmetric hypothesis. Psychometrika, 29, 1-27. http://dx.doi.org/10.1007/BF02289565

LePine, J. A., \& Van Dyne, L. (2001). Voice and cooperative behavior as contrasting forms of contextual performance: Evidence of differential relationships with Big Five personality characteristics and cognitive ability. Journal of Applied Psychology, 86, 326-336. http://dx.doi.org/10.1037/0021-9010.86.2.326

Liden, R. C., \& Maslyn, J. M. (1998). Multidimensionality of leader-member exchange: An empirical assessment through scale development. Journal of Management, 24, 43-73. http://dx.doi.org/10.1016/S0149-2063(99)80053-1

Liden, R. C., Erdogan, B., Wayne, S. J., \& Sparrowe, R. T. (2006). Leader-member exchange, differentiation, and task interdependence: Implications for individual and group performance. Journal of Organizational Behavior, 27, 723-746. http://dx.doi.org/10.1002/job.409

Liden, R. C., Sparrowe, R. T., \& Wayne, S. J. (1997). Leader-member exchange theory: The past and potential for the future. In G. R. Ferris (Ed.), Research in personnel and human resources management (vol. 15, pp. 47-119). Oxford, UK: Elsevier.

Lo, Y., Mendell, N., \& Rubin, D. (2001). Testing the number of components in a normal mixture. Biometrika, 88, 767-778. http://dx.doi.org/10.1093/biomet/88.3.767

MacKinnon, D. P., Lockwood, C. M., Hoffman, J. M., West, S. G., \& Sheets, V. (2002). A comparison of methods to test mediation and other intervening variable effects. Psychological Methods, 7, 83-104. http://dx.doi.org/10.1037/1082-989X.7.1.83

Mathieu, J. E., \& Taylor, S. R. (2007). A framework for testing meso-mediational relationships in organizational behavior. Journal of Organizational Behavior, 28, 141-172. http://dx.doi.org/10.1002/job.436

Mathieu, J. E., Martineau, J. W., \& Tannenbaum, J. I. (1993). Individual and situational influence on the development of self-efficacy: Implications for training effectiveness. Personnel Psychology, 46, 125-147. http://dx.doi.org/10.1111/j.1744-6570.1993.tb00870.x

Matsunaga, M. (2007). Familywise error in multiple comparisons: Disentangling a knot through a critique of O'Keefe's arguments against alpha adjustment. Communication Methods \& Measures, 1, 243-265. http://dx.doi.org/10.1080/19312450701641409

McGraw, A. P., Larsen, J. T., Kahneman, D., \& Schkade, D. (2010). Comparing gains and losses. Psychological Science, 21, 1438-1445. http://www.jstor.org/stable/41062504

Meglino, B. M., \& Korsgaard, A. (2004). Considering rational self-interest as a disposition: Organizational implications of other orientation. Journal of Applied Psychology, 89, 946-959. http://dx.doi.org/10.1037/0021-9010.89.6.946

Menard, S. W. (2002). Longitudinal research (2nd ed.). Thousand Oaks, CA: Sage.

Mesmer-Magnus, J. R., \& DeChurch, L. A. (2009). Information sharing and team performance: A meta-analysis. Journal of Applied Psychology, 94, 535-546. http://dx.doi.org/10.1037/a0013773

Milliken, F. J., Morrison, E. W., \& Hewlin, P. F. (2003). An exploratory study of employee silence: Issues that employees don't communicate upward and why. Journal of Management Studies, 40, 1453-1476. http://dx.doi.org/10.1111/1467-6486.00387

Morrison, E. W., \& Milliken, F. J. (2000). Organizational silence: A barrier to change and development in a pluralistic world. Academy of Management Review, 25, 706-725. http://dx.doi.org/10.5465/AMR.2000.3707697 
Morrison, E. W., Wheeler-Smith, S. L., \& Kamdar, D. (2011). Speaking up in groups: A cross-level study of group voice climate and voice. Journal of Applied Psychology, 96, 183-191. http://dx.doi.org/10.1037/a0020744

Muthén, B. O. (1994). Multilevel covariance structure analysis. Sociological Methods \& Research, 22, 376-398.

Muthén, B. O. (2002). Beyond SEM: General latent variable modeling. Behaviormetrika, 29, 81-117. http://doi.org/10.2333/bhmk.29.81

Muthén, L. K., \& Muthén, B. O. (2006). Mplus user’s guide. Los Angeles: Muthén \& Muthén.

Northcraft, G., \& Neale, M. (1986). Opportunity costs and the framing of resource allocation decisions. Organizational Behavior \& Human Decision Processes, 37, 348-356. http://dx.doi.org/10.1016/0749-5978(86)90034-8

O’Keefe, D. J. (2002). Persuasion: Theory \& Research. Thousand Oaks, CA: Sage.

Omarzu, J. (2000). A disclosure decision model: Determining how and when individuals will self-disclose. Personality and Social Psychology Review, 4, 174-185. http://dx.doi.org/10.1207/S15327957PSPR0402_05

Payne, J. W., Bettman, J. R., \& Luce, M. F. (1996). When time is money: Decision behavior under opportunity-cost time pressure. Organizational Behavior \& Human Decision Processes, 66, 131-152. http://dx.doi.org/10.1006/obhd.1996.0044

Petronio, S. (1991). Communication boundary management: A theoretical model of managing disclosure of private information between marital couples. Communication Theory, 1, 311-335. http://dx.doi.org/10.1111/j.1468-2885.1991.tb00023.x

Petronio, S. (2002). Boundaries of privacy: Dialectics of disclosure. Albany, NY: SUNY Press.

Raudenbush, S. W., \& Bryk, A. S. (2002). Hierarchical linear models: Applications and data analysis methods (2nd ed.). Thousand Oaks, CA: Sage.

Rimal, R. N., \& Real, K. (2005). How behaviors are influenced by perceived norms: A test of the theory of normative social behavior. Communication Research, 32, 389-414. http://dx.doi.org/10.1177/0093650205275385

Roloff, M. E., \& Cloven, D. H. (1990). The chilling effect in interpersonal relationships: The reluctance to speak one's mind. In D. D. Cahn (Ed.), Intimates in conflict: A communication perspective (pp. 49-76). Hillsdale, NJ: LEA.

Samuelson, W., \& Zeckhauser, R. (1988). Status quo bias in decision making. Journal of Risk and Uncertainty, 1, 759. http://dx.doi.org/10.1007/BF00055564

Scandura, T. A., \& Graen, G. B. (1984). Moderating effects of initial leader-member exchange status on the effects of a leadership intervention. Journal of Applied Psychology, 69, 428-436. http://dx.doi.org/10.1037/0021-9010.69.3.428

Scandura, T. A., \& Schriescheim, C. A. (1994). Leader-member exchange and supervisor career mentoring as complementary constructs in leadership research. Academy of Management Journal, 37, 1588-1602. http://dx.doi.org/10.2307/256800

Seers, A. (1989). Team-member exchange quality: A new construct for role-making research. Organizational Behavior \& Human Decision Processes, 43, 118-135. http://dx.doi.org/10.1016/0749-5978(89)90060-5

Sias, P. M., \& Jablin, F. M. (1995). Differential superior-subordinate relations, perceptions of fairness, and coworker communication. Human Communication http://dx.doi.org/10.1111/j.1468-2958.1995.tb00360.x

Signer, J. D., \& Willett, J. B. (2003). Applied longitudinal data analysis: Modeling change and event occurrence. Oxford, U.K.: Oxford University Press.

Simon, H. A. (1991). Bounded rationality and organizational learning. Organization Science, 2, 125-134. http://dx.doi.org/10.1287/orsc.2.1.125

Simons, T., \& Roberson, Q. (2003). Why managers should care about fairness: The effects of aggregate justice perceptions on organizational outcomes. Journal of Applied Psychology, 88, 432-443. http://dx.doi.org/10.1037/0021-9010.88.3.432

Sobel, M. E. (1982). Asymptotic confidence intervals for indirect effects in structural equation models. In S. Leinhart (Ed.), Sociological methodology (pp. 290-312). San Francisco: Jossey-Bass. 
Sparrowe, R. T., \& Liden, R. C. (2005). Two routes to influence: Integrating leader-member exchange and social network perspectives. Administrative Science Quarterly, 50, 505-535. http://www.jstor.org/stable/30037220

Tangirala, S., \& Ramanujam, R. (2008). Employee silence on critical work issues: The cross level effects of $\begin{array}{lllll}\text { procedural justice } & \text { Plimate. }\end{array}$ http://dx.doi.org/10.1111/j.1744-6570.2008.00105.x

Tversky, A., \& Kahneman, D. (1991). Loss aversion in riskless choice: A reference-dependent model. Quarterly Journal of Economics, 106, 1039-1061. http://dx.doi.org/10.2307/2937956

Umphress, E. E., Labianca, G., Brass, D. J., Kass, E., \& Scholten, L. (2003). The role of instrumental and expressive social ties in employees' perceptions of organizational justice. Organization Science, 14, 738-753. http://dx.doi.org/10.1287/orsc.14.6.738.24865

Van Dyne, L., \& LePine, J. A. (1998). Helping and voice extra-role behavior: Evidence of construct and predictive validity. Academy of Management Journal, 41, 108-119. http://dx.doi.org/10.2307/256902

Van Dyne, L., Ang, S., \& Botero, I. (2003). Conceptualizing employee silence and voice as multidimensional constructs. Journal of Management Studies, 40, 1359-1392. http://dx.doi.org/10.1111/1467-6486.00384

Vangelisti, A. L., Caughlin, J. P., \& Timmerman, L. (2001). Criteria for revealing family secrets. Communication Monographs, 68, 1-17. http://dx.doi.org/10.1080/03637750128052

Venkataramani, V., \& Tangirala, S. (2010). When and why do central employees speak up? An examination of mediating and moderating variables. Journal of Applied Psychology, 95, 582-591. http://dx.doi.org/10.1037/a0018315

Vermunt, J. K., \& Magidson, J. (2002). Latent class cluster analysis. In J. A. Hagenaars \& A. L. McCutcheon (Eds.), Applied latent class analysis (pp. 89-106). New York: Cambridge University Press.

Welbourne, J., \& Booth-Butterfield, S. (2005). Using the theory of planned behavior and a stage model of persuasion to evaluate a safety message for firefighters. Health Communication, 18, 141-154. http://dx.doi.org/10.1207/s15327027hc1802_3 